\title{
The Puzzle of the Difficulties in Education Burden Reduction- Based on Conflict Perspective
}

\author{
Ying Xie \\ School of Education Science \\ Nanjing Normal University 210097 \\ China \\ Liuxi Chu \\ School of Biological Sciences \& Medical Engineering \\ Key Laboratory of Child Development and Learning Science (Southeast University) \\ Ministry of Education, and Institute of Child Development and Education \\ Southeast University, Nanjing 210096, China
}

\begin{abstract}
China's request for the reduction of basic education has been going on for five decades, but the effect was little. From the perspective of conflicts in sociology to trace the reasons for the inefficiency of the burden reduction policy, are mainly due to the existence of behavioral conflicts among the participating subjects. The main reasons behind the conflicts are: the conflict between the burden reduction and the current educational values, and participation in the burden reduction body. Besides, there is a conflict between the interests of the government, and there is a conflict between the statutory power of the government and the civil liberties. In view of the above reasons, the author believes that it can be solved from the following aspects: from burden reduction to increasing the compensation of the weak sectors of education, from policy reduction to systemic burden reduction, from a single evaluation standard to the construction of a multi-evaluation system.
\end{abstract}

Keywords: Basic education, burden reduction, conflict

Education burden reduction continues to receive widespread attention, but the results received are not ideal, and even the negative effects of no reduction or increase. Why is it so difficult to reduce the burden?

\section{Research on burden reduction from the perspective of different disciplines}

In response to this problem, the existing research is mainly divided into three categories: one is policy-based research from the perspective of political science, such as the historical retrospective analysis of the published burden-reduction policy text, summarizing the evolution trend of the burden-reduction policy ${ }^{[1-5]}$, or the formulation of policies implementation, and supervision to analyze the problems arising from the burden reduction policy ${ }^{[6-8]}$. Second is the perspective of economics. Through the analysis of the time and space allocation model of students' academic burden, the reasons for the difficulty of reducing the burden ${ }^{[9]}$, and the classical game theory of economics are used to analyze the behavior of the burden-reducing subject in the predicament ${ }^{[10-12]}$. The third is the perspective of education, from the perspective of curriculum and teaching to explore how to reduce burdens, such as changing the curriculum plan, planning and sourcing from the source. Simple curriculum standards and textbooks, or the use of classroom time in a highly effective manner, improve the efficiency of teaching in all subjects, thereby reducing the academic burden of students in their spare time ${ }^{[13-15]}$.

Different disciplines have their own "eyes", the so-called eye of the discipline. The content seen by different disciplines is different. Different people represent different angles and eventually merge into a whole picture, which deepens our understanding of the problem.

\section{The burden reduction problem from the perspective of conflict}

The "stubborn disease" of "the burden of students" schoolwork is not only related to educational internal factors such as educational concepts, educational content, teaching difficulty, teaching methods, examination system, and teacher quality, but external aspects such as family background, employment form, and social culture ${ }^{[16]}$. The analysis of the burden reduction of basic education cannot be limited to the perspective of policy and pedagogy, but should focus on the entire social system. 
This paper provides a new perspective on conflicts based on the entire social system, where people in different locations in the system are struggling due to differences in values, beliefs, or scarcity status, resource needs, looking at the burden of the education system. The entire social environment to analyze the reasons for the difficulty of reducing the burden.

\subsection{Conflicts of participating entities: parents, education administration, school teachers and}

The three main players involved in education reduction are the administrative department, school teachers, and parents. The behavior between them is uncoordinated and contradictory, and the parent groups are complex, with different social situations and different interests. Therefore, clarifying the conflict behaviors of the three major subjects can be better understand why education reduction has little effect.

\subsubsection{Conflicts within parent groups}

Since the reform and opening up, with the advancement of the economic system and the advancement of the modernization process, China's social structure has undergone tremendous changes. The traditional pyramid structure has been transformed into two small, medium-sized olive structures, which can be roughly divided into elite and middle classes $^{[17-18]}$. Three types of social groups with the social workforce. The composition of the parent group is complex and diverse. They have different occupations, educational backgrounds, and economic status. Therefore, their expectations and demands for education are inconsistent and even contradictory. The economic, cultural and social capital provided by varied classes for their children are very different, and the accumulation and the return of capital further expand this inequality in education.

First of all, in the education concept of the elite, education is an elegant activity to improve the quality of life. They pay attention to the intrinsic value of education and the future of students rather than accurately calculating the students' eyes. They are willing to cultivate their children's interests, tastes, abilities, and support for burden reduction, so that children have time to broaden their horizons and learn more skills outside of school.

Secondly, social status and class are measured by one or more indicators of income, occupation, education, and social prestige. The rise of the middle class in our society is undeniable. Different from the elite and the working class, the middle class parents have higher educational expectations and can translate higher education expectations into rational strategies. They use their social, economic and cultural capital to invest in their children's education. Positive actions that benefit children's education. Parents of the middle class show contradictory educational behavior. On the one hand, they support the progressive education concept, advocate education to utilitarianism, and support to reduce the burden of students' schoolwork; on the other hand, they report their children to each other with a conservative attitude. Kindergarten classes, which increase the child's academic burden. The middle class recognizes the pressure of the job market and understands the importance of the function and diploma of education. They are the runners of the education system competition. For the burden reduction, they completely approve.

The social economic and cultural capital are relatively weak. There is not much resources and ability to provide children with a worry-free future, and only education provides them with the possibility of upward mobility. However, parents of the social working class tend to be passively accepted for education, adopt a laissez-faire attitude toward their children's learning, and regard their children's learning as the responsibility of schools and teachers. This kind of passiveness also involves the ability to tutor students' academic work. Because such parental diplomas are generally not high, they limit their educational actions. They believe that the root of educational achievement lies in the qualifications, talents and efforts of the learners themselves, and has nothing to do with the family. This kind of cognition weakens the motivation of the social labor class parents to participate in education. In addition, the social labor class parents are busy with work, have no time and economic conditions to support their children to participate in additional tutoring, so they hope that school teachers can take on more counseling responsibilities, and they are mostly negative about reducing their burdens. The elite class regards education as an elegant activity to improve oneself. It is an ideal ultimate value. The middle class and the social labor class parents regard education as a tool for upward mobility and a tool value. For decades of basic education reform, should we uphold the concept of progressive education or traditional education? Further, is it to insist on elite education or to choose mass education? Education is difficult to balance the educational needs of conflicts, and even more so.

\subsubsection{Conflict between the education administration and the school and parents}

On the one hand, primary and secondary school students work overtime, and parents complain that the education administration has issued a burden-reduction document in response to public appeals and public opinion pressure. On the other hand, according to the "China Youth and Children Development Status" survey conducted by the China Youth Research Center in 2015, "the primary school students' work time exceeded 66\%, and the junior high school students' over-standard rate exceeded $78 \%$. 
On the rest day, primary and secondary school students the over-standard rate of homework is over $80 \%$; the student's study day is no more than one hour of $66.3 \%$; the tutoring time also leads the world." Over-heavy of primary and secondary school students has become a social problem. The introduction of a policy of reducing burdens can, to a certain extent, force the continued development of the situation. Moreover, the society's demand for talents is diversified, rather than a machine that only endorses the problem, and reducing the burden of students' work can lead to more opportunities to cultivate students' comprehensive ability. The education administration is actively trying to guide the public to a sustainable educational concept rather than a utilitarian education concept. However, this decision does not have a set of implementation plans based on the entire education system, but simply from the policy. At the level, try to alleviate the excessive academic burden on students ${ }^{[19-23]}$. This has created a confrontation and conflict between the burden-reduction policy and the real ecology of the entire education system. Because for schools and teachers, responding to policy requirements, simply reducing the workload of students will only affect the quality of teaching, which is not conducive to the rate of school entrance and performance evaluation, and the assessment criteria for schools and teachers are only indicators of achievement.

\subsection{Reasons for conflict: values, interests and powers}

In the face of frequent reductions issued by the education administration, school teachers cooperate with superiors on the one hand to increase academic pressure on students. Parent groups are complex and diverse, and different levels of attitudes toward burden reduction are different, but the actions of mainstream parent groups are also contrary to burden reduction. What are the reasons behind these conflicting behaviors? This paper argues that there are three main conflicts between these subjects, namely, values, interests and power.

\subsubsection{Conflict between the burden reduction policy and the current educational value}

The burden-reduction policy not only conflicts with the current educational value, but also runs counter to the real educational situation. In the real educational situation, the daily focus of the school is how to improve the quality of teaching and the rate of enrollment. The daily concern of teachers is how to make students acquire knowledge more firmly and get good grades so that they can get higher performance at the end of the period. Parents mainly focus on how to make their child to enroll in a good school, and how to get higher scores. In the traditional concept of education, education is more about the transfer of knowledge, the tools of upward mobility, and the ladder of changing fate. This kind of tool education value is the real existence in the education ecology, and it is the alienation of education in the whole utilitarian society, but it is unavoidable.

Secondly, the conflict between the value expectation of education and the policy of reducing the burden. The high value expectation of Wang Zicheng and Wang Nongcheng has intensified the demand for education quality and quantity, thus exacerbating competition. Since the one-child policy of 1978 was written into the Constitution, the policy of "a couple raising only one child" has led to the "only" mentality and "all hope" mentality of parents. The "only" mentality causes parents to be anxious, lest the children not be satisfied, and increase the parents' specific expectations of the education level of "single seedlings" and the future career direction. The "all hope" mentality has made all the hopes of parents and the whole family fall on one child. It is not surprising that "pull the seedlings" and "win at the starting line" and look for various cram schools and special classes. This high educational value expectation is deeply rooted in the hearts of every parent and conflicts with the burden-reduction policy.

Finally, the conflict between the education evaluation system and the burden reduction, the conflict between the system and the policy is actually remarkable. Under the value evaluation based on the score, the teaching activities are carried out around the examination, and all the policy measures related to the liberation of children are not enough to incite the examination as the educational foundation of the Lord. The examination is getting harder and harder, and the teaching efficiency is not improved. Students can only choose to study hard and hard work, and it is difficult to achieve results by reducing the burden.

\subsubsection{Conflict between the burden reduction policy and the economic interests of the various entities}

Diversification of the subject, diversification of interests, and complexity of the performance, resulting in a place where there is a relationship, will lead to conflict. First, the same is the education administrative department. The Ministry of Education formulates educational policies and policies, and co-ordinates the national education development plan. It appears as the mediator of the interests and the makers of the general rules. Based on the analysis of the expected benefits of the cost and benefits of the change of rules. Through policy adjustments, respond to people's educational demands and promote the development of education and society. The local education bureau is attached to local fiscal revenue, and education is one of the main achievements of local governments. Therefore, the local education bureau responds to the burden reduction policy of the higher education department on the one hand, and exerts pressure on the school on the one hand according to the needs of its own interests. 
Second, reduce the burden of interest and conflicts between schools and teachers. The policies of the Ministry of Education are always single and changeable. School teachers cannot carry out all-round teaching reform according to a single burden-reduction policy, and responding to policies means changing old teaching habits, which means spending more thoughts and undertaking more. More risks, less gains, so schools and teachers usually take the "unchanged" policy.

Third, the burden of reduction and the conflict of interest of parents. The burden reduction is unfavorable for most middle-class and working-class parents, because parents need to spend more energy and financial resources to go to the school for tutoring and tutoring. For families without financial ability, the burden is not Conducive to educational equity.

\subsubsection{The conflict between the government's statutory power and the right to civic education}

In the process of reducing the burden, the government has a dominant position, and even if the school has different views on the burden reduction at the level of values or interests, it can only obey the document instructions. The inequality at the power level led the school to cope with the government's inspection of the burden reduction work, and on the other hand secretly compensate students. The government's authority is limited. It is impossible to reach all aspects of people's lives, and it is impossible to restrict and limit every behavior of people. The burden-reduction policy can only restrict school behavior, but it cannot restrict social education institutions and family education rights. The "freedom of discretion" of people's behavior is very large. For parents, he is free to choose a training institution for students and has the right to increase their homework. The "burden reduction" policy can only restrict the educational actions of the school, but not the social

Education activities for educational institutions and families. For example, the "burden reduction" policy cannot prohibit social individuals or groups from setting up various training schools or restricting the enrollment targets of training schools. For social training institutions, as long as it is legally operated, it has the right to give students a good job, which is society. The conflict between educational power and government power, and policies can do nothing, which is also an important reason why the burden is so difficult.

\subsection{From conflict to checks and balances}

\subsection{1 from burden reduction to increasing education compensation for vulnerable groups}

For the burden-reduction policy, different actors have adopted conflicting behaviors based on their respective positions, and have not formed a burden reduction force. The main reason is that burden reduction involves the entire society and every family, not just the school education system. The main body is diverse, the classes are different, and sometimes it is difficult to achieve unity. As far as the parent group is concerned, their educational goals are the same. Some recognize traditional school education and rely on the upward path of exam-oriented education. Some require changes in traditional school education and strengthen family education and market-oriented education. It is difficult for the education system to balance the needs of opposing education. If the implementation of the burden reduction policy alone will definitely lead to the disadvantaged situation of the disadvantaged class in education. To reflect on the policy of reducing burdens, the government should stick to the education bottom line of caring for the disadvantaged. In addition, regional differences, urban-rural differences and other factors have caused the disadvantaged groups to become more vulnerable in education, and rural students lack social education in the form of counseling. Under the burden-reduction policy, academic performance has declined significantly. Therefore, the government and schools should implement a free education compensation policy to provide free counseling for children of the working class and rural students, improve the community education function, and provide opportunities and support for the mobility of children from disadvantaged families.

\subsection{2 from policy burden reduction to systemic burden reduction}

School teachers' behaviors of reducing and increasing student's academic burden are derived from the unity of the burden-reduction policy. It is due to the fact that the burden reduction does not touch the overall planning of the whole classroom teaching. Therefore, from the curriculum to the teaching, we must go through such a theoretical and practical process. : First, there must be a curriculum plan to plan the course categories and total amount; the curriculum content and teaching tasks are stipulated by the curriculum standards to determine their academic standards and indicators; and then the textbooks and teaching tasks are compiled and presented. Finally, the classroom teaching is implemented as the actual learning and learning of the students. To reduce the burden cannot simply reduce the after-school homework through the red-headed document, but should involve the improvement of the whole curriculum planning, content and teaching level. Otherwise, it will inevitably lead to the decline of teaching quality and affect the performance evaluation of schools and teachers. 


\subsection{3 from a single evaluation standard to a multi-evaluation system}

The implementation of the "burden reduction" policy also requires the protection of the relevant education system. The current evaluation system based on scores is in conflict with the burden reduction. Although this evaluation system maintains education equity to a certain extent, it is the inversion of all aspects of the evaluation of the education process. If the performance of the school and the teachers are evaluated by the rate of enrollment, the evaluation system of the students will be determined by the scores, and the burden reduction will not be discussed. The administrative department of education should link up the burden reduction work with the whole system of junior high and early rise, and the college entrance examination system. Under the premise of adhering to educational equity and social needs, the evaluation mechanism should be flexibly changed to remove the obstacles to the evaluation system.

\section{References}

Luo Jianhe. Analysis of the Limits of the "Reduce the Burden" Policy [J]. Copying Newspapers and Periodicals: Primary and Secondary Education, 2009(11): 17-19.

Xie Limin. Historical Retrospection and Reflection on the Problem of "Lightening the Burden" in China for Half a Century [J]. Journal of Jimei University, 2005, 6(3): 21-26.

Wen Yali. The evolution and analysis of China's policy to alleviate the burden of students' excessive work[J]. Journal of Henan Normal University (Philosophy and Social Sciences),2012, 39(6):240-242.

Yang Chunni. Realistic difficulties and countermeasures in the implementation of the "burden reduction" policy for primary school students [J]. Modern Primary and Secondary Education, 2017, 33(1): 8-11.

Xiao Yuanjun, Li Chunling. Analysis of the Causes of the Distortion of the Burden Reduction Policy in Primary and Middle Schools[J]. Journal of Zhejiang International Studies University, 2007(6): 12-16.

Zhang Zhaoying, Zheng Donghui. How is "burden reduction" possible: analysis of national burden reduction policy based on high frequency vocabulary [J]. Shanghai Education and Research,2016(3):5-9.

$\mathrm{Xu}$ Hui. Research on the burden reduction policy of primary and secondary schools in China since the reform and opening up [J]. Curriculum Teaching Research, 2014(12): 29-34.

Wang Xiaoli. The evolution and thinking of the "burden reduction" policy for basic education since the founding of the People's Republic of China [J]. Education and Examination, 2009(5): 77-80.

Ma Jiansheng, Wu Jiani. Why is the student's burden reduction policy difficult to achieve results?_ On the nature and mechanism of the time distribution of academic burden [J].

Beijing Journal of Normal University (Social Science Edition), 2014(2): 5-14.

Ren Zixiong. Game Analysis of the Reduction of Basic Education[J]. Education Science, 2008, 24(4): 17-20.

Wen Xue, Yan Zhongping. From the perspective of game theory, "education reduction" [J]. China Education Journal, 2007(1): 22-24.

Xu Benyu. Why the education burden is invalid: based on the perspective of game theory [J]. Reform and opening up, 2017(13): 148-150.

Huang Wei. "Lightening the burden": the role and role of curriculum and teaching [J]. Educational Development Research, 2013(24): 41-45.

Zhang Guocheng, Lin Xindi. Strategies for reducing burdens and increasing efficiency in classroom teaching in middle schools [J]. China Education Journal, 2006(4): 47-51+55.

Wu Qunfang. Approaches to reduce burdens and increase efficiency in primary school Chinese teaching [J]. New Curriculum Research (early issue), 2011(1): 107-107.

Xiao Yuanjun, Li Chunling. Analysis of the Causes of the Distortion of the Burden Reduction Policy in Primary and Middle Schools[J]. Journal of Zhejiang International Studies University, 2007(6): 12-16

Zhang Wenhong, Su Di. Cultural Capital, Economic Capital and Class Reproduction [J]. Jianghai Academic Journal, 2018(03): 102-112

Lu Xueyi. Analysis of the Top Ten Strata in Contemporary Chinese Society [J]. Learning and Practice, 2002(03): 55-63.

Li Chunling. The development trend of China's middle class and its challenges [J]. Journal of the Central Institute of Socialism, 2018 (04): 13-16.

Li Qiang. Social stratification, middle class and middle income group [J]. Journal of the Central Institute of Socialism, 2018 (04): 5-12.

Huang Yuexi, Huang Chudan. The influence of class solidification on youth "national identity" consciousness and countermeasures [J]. Journal of Guizhou Party School, 2018 (04): 102-108.

Huang Yuexi, Huang Chudan. The Influence of Class Solidification on Youth's "National Identity" Consciousness and Countermeasures [J]. Guizhou Provincial Party SchoolNewspaper, 2018 (04): 102-108.

Jiang Tianhui. The causes of unequal education results: rational capital and educational actions of parents of different social classes [J]. Tsinghua University Education ResearchResearch, 2010, 31 (06): 19-26 + 63. 